\title{
The Rate and Risk Factors of Pospartum Depression in Sana'a Yemen
}

\author{
Athmar Hussein Ali ${ }^{1}$, Amat-Al Karem Ali Hamad Al Huri ${ }^{1}$, Kaima Abdullah Frass ${ }^{1}$, \\ Abdelrahman Hasan Al Harazi ${ }^{2, *}$ \\ ${ }^{1}$ Department of Obstetrics and Gynecology, Faculty of Medicine, Sanaa University, Sana'a, Yemen \\ ${ }^{2}$ Obstetrics and Gynecology Department, Faculty of Medicine, Thamar University, Sana'a, Yemen

\section{Email address:} \\ Athmarali265@gmail.com (Athmar H. A.), osama.m.alshami@gmail.com (Amat-Al K. A. H. Al H.), \\ kaimafrass@hotmail.com (Kaima A. F.), alharazi77184@ho tmail.com (Abdelrahman H. Al H.) \\ ${ }^{*}$ Corresponding author
}

\section{To cite this article:}

Athmar Hussein Ali, Amat-Al Karem Ali Hamad Al Huri, Kaima Abdullah Frass, Abdelrahman Hasan Al Harazi. The Rate and Risk Factors of Pospartum Depression in Sana'a Yemen. Journal of Gynecology and Obstetrics. Vol. 5, No. 3, 2017, pp. 37-41.

doi: $10.11648 /$ j.jgo.20170503.11

Received: April 22, 2017; Accepted: May 2, 2017; Published: May 24, 2017

\begin{abstract}
This cross - sectional study was done to assess the rate and risk factors of postpartum depression among women who had given birth between $4-6$ weeks prior to interview in four public medical centers of Sana'a city over a period from February to July 2016. We administered the Edinburgh postnatal Depression Scale to 642 women. Among these, 97 women had scored $\geq 12$, giving the rate of $15.1 \%$ of postpartum depression. Mothers with this condition were more likely to have unwanted pregnancy, recent conflict with husbands / family, financial hardship, anxiety and health problems during pregnancy, and difficulties in breastfeeding. The study revealed a high rate of postpartum depression. Although it is recognized that timing and ideal interval for screening is unknown such screening would increase detection, treatment and improve health outcomes of women and their children.
\end{abstract}

Keywords: Postpartum Depression, Prevalence, Risk Factors

\section{Introduction}

Postpartum depression (PPD) is defined as a depressive episode that is temporarily associated with childbirth [1]. Childbirth can trigger a variety of psychiatric illnesses including mood disorders. The term "postpartum mood disorders "generally refers to the baby blues, PPD, and puerperal psychosis [2]. PPD may occur any time after delivery up to one year postpartum and is the most common psychiatric complication of childbirth, affecting $10 \%$ to $15 \%$ of women who have recently given birth [3]. PPD is a nonpsychotic depressive disorder that starts in or extends into postpartum period up to twelve months after delivery. It consists of any or a combination of sleeping and eating disturbances, mental confusion, loss of self - esteem, anxiety, lack of interest in one's environment, insecurity and suicidal thoughts [4]. If left untreated, PPD is associated with potentially adverse consequences for the mother, her infant, and the family. There is a high risk of recurrence $50-100 \%$ in subsequent pregnancies [5]. Multiple risk factors for PPD have been suggested as no single cause has been identified. Depression or anxiety during pregnancy, stressful events during pregnancy or in the early puerperium, low levels of social support, and a personal or family history of depression are strong risk factors of PPD [6]. However, not all women with these risk factors suffer from depression [7]. For this reason, early screening for PPD would increase detection, treatment, and improve health outcomes of women and their children [1]. The Edinburgh Postnatal Depression Scale (EPDS) is commonly used to measure severity of depression in the postnatal period and to estimate the presence of PPD [8]. The aim of this study was to assess the rate of PPD among women who delivered within $4-6$ weeks prior to screening using EPDS, and to evaluate the risk factors associated with PPD. 


\section{Methods and Materials}

This is a cross - sectional study conducted over 7 months (From February to July 2016) in four public clinical centers within the Sana'a city. These centers are Azal medical center, Al Zahrawi medical center, Ali Abdul Moghni medical center and the Maternity Center of Al Sabaeen hospital. The approval of the study protocol was obtained from the ethics committee of Al Sabaeen hospital and the verbal consent was obtained from each respondent. Respondents were recruited from postnatal clinics of these centers. Six hundred forty two women were included in this study. The inclusion criteria were delivery within $4-6$ weeks and having a live baby at the time of interview. We excluded all known cases of mental illnesses or under mental medication, and mothers of twins or triplets. A questionnaire was prepared and included all obstetrics and sociodemographic information such as age, parity, complications during pregnancy, whether the pregnancy was planned, marital status, socioeconomic status, residence settings, stressful events, mode of delivery, intra and postpartum complications, and fetal outcome.

The questionnaire was filled through direct interview. Evaluation of depression was conducted through self rating for depression using the Edinbrugh Postpartum Depression Scale (EPDS). Different scores were given based on the best response of the mothers. A cut off point score of $\geq 12$ was used to determine whether the mother had depression or not. For easy understanding of the EPDS, it was in both English and Arabic format. Assistance was available to those who had concerns of not understanding the scale well. Completion of the data-collecting instrument was done at the same time of the interview. All the women with a score $\geq 12$ were referred to a psychiatric center for a specialized care. IBM SPSS (version 22) was used to perform all statistical analyses. Data were analyzed using Chi-square and Fisher's exact test. Risk factors were identified by calculating the odds ratio (OR) with a 95\% confidence interval (CI). Pvalues less than 0.05 indicate statistical significance.

\section{Results}

There were 642 women screened by EPDS. Of these, 97 women had a score of $\geq 12$ and considered having postpartum depression, giving a rate of $15.1 \%$.

Among women who scored positive for PPD, there were $62.9 \%$ aged $\geq 24$ years, $78.3 \%$ were multiparas, $39.1 \%$ had not educated and $70 \%$ were housewives. There were no significant differences with those scored negative in these variables (Table 1)

Recent pregnancy was reported as unwanted by $51.1 \%$ among women scored positive compared to $5.8 \%$ of women scored negative. The difference was significant (OR 17.0, 95\% CI $9.9-29.1, p<0.00$ ). The partner's support was perceived as inadequate by $45.3 \%$ of women with PPD. The difference with women who had no PPD was significant (OR $1.5,95 \%$ CI $1.0-2.4, p$. 04). Recent conflict with husband and / or family was present in $68 \%$ of women scored positive compared to $23.1 \%$ of women scored negative. The difference between the two groups was significant (OR 7.0, $95 \%$ CI $4.4-11.3, p<0.00$ ). Pregnancy health problems were reported by $75.2 \%$ among women scored positive versus $15 \%$ of women scored negative. The difference was significant (OR 17.1, 95\% CI $10.2-28.8, p<0.00$ ). Economic problems were reported by $66 \%$ of women with PPD compared to $34.3 \%$ of their counterparts (OR 3.7, 95\% CI $2.35-5.85 p<0.00)$. Newborn health problems were found in $30.9 \%$ of women with PPD versus to $4.9 \%$ of women with no PPD. The difference between the two groups was significant (OR 2.35, 95\% CI $1.4-3.8, p=.000$ ). Breastfeeding difficulties were present among $22.7 \%$ of women scored positive for PPD versus $4.9 \%$ of women who scored negative (OR 5.6, 95\% CI $3.0-10.3, p<0.00$ ). There were no difference of the frequency of caesarian section performed for the study group and women with negative PPD $(12.3 \%$ and $12.2 \%)$ respectively. Table 2 shows the recognized factors associated with PPD.

Table 1. Socio demographic characteristics of women screened by EPDS.

\begin{tabular}{|c|c|c|c|c|}
\hline \multirow{2}{*}{ Variable } & \multicolumn{2}{|l|}{ PPD } & \multirow[b]{2}{*}{ OR $95 \%$ CI } & \multirow[b]{2}{*}{ P value } \\
\hline & Yes $($ EPDS) $\geq 12$ & No (EPDS) $<12$ & & \\
\hline \multicolumn{5}{|l|}{ Age $(Y)$} \\
\hline$<24$ & $36(37.1)$ & $207(38)$ & \multirow{3}{*}{$0.96,0.61-1.5$} & \multirow{3}{*}{0.87} \\
\hline$\geq 24$ & $61(62.9)$ & $338(62)$ & & \\
\hline \multicolumn{3}{|l|}{ Parity } & & \\
\hline Primipara & $21(21.6)$ & 114 (20.9) & \multirow{3}{*}{$1.0,0.61-1.7$} & \multirow[t]{2}{*}{0.87} \\
\hline Multipara & $76(78.3)$ & $431(79)$ & & \\
\hline \multicolumn{4}{|c|}{ Material status } & \\
\hline Married & $86(88.7)$ & $480(88)$ & \multirow{3}{*}{$1.0,0.53-2.0$} & \multirow[t]{3}{*}{0.86} \\
\hline Divorced & $11(11.3)$ & 65 (11.9) & & \\
\hline \multicolumn{3}{|l|}{ Education } & & \\
\hline Illiterate & $38(39.1)$ & $182(33.3)$ & $1.2,0.82-2$ & 0.26 \\
\hline Primary & $23(23.7)$ & $164(30)$ & $0.7,0.43-1.1$ & 0.20 \\
\hline Secondary & $26(26.8)$ & $170(21.1)$ & $0.86,0.49-1.3$ & 0.38 \\
\hline High & $10(10.3)$ & $29(5.3)$ & $2.0,0.96-4.3$ & 0.06 \\
\hline \multicolumn{5}{|l|}{ Occupation } \\
\hline House wife & $68(70)$ & $404(74.1)$ & \multirow{3}{*}{$0.8,0.50-1.3$} & \multirow{3}{*}{0.40} \\
\hline Employee & $29(29.1)$ & $141(25.9)$ & & \\
\hline Abortion hx & & & & \\
\hline Yes & $34(35)$ & $54(9.9)$ & $4.9,2.9-8.1$ & $<0.001$ \\
\hline
\end{tabular}




\begin{tabular}{|c|c|c|c|c|}
\hline \multirow{2}{*}{ Variable } & \multicolumn{2}{|l|}{$\overline{\text { PPD }}$} & \multirow{3}{*}{ OR $95 \%$ CI } & \multirow{2}{*}{ Pvalue } \\
\hline & Yes $($ EPDS) $\geq 12$ & No (EPDS) $<12$ & & \\
\hline No & $63(65)$ & $491(90)$ & & \\
\hline \multicolumn{5}{|c|}{ Previous hx of PPD } \\
\hline $\begin{array}{l}\text { Yes } \\
\text { No }\end{array}$ & $\begin{array}{l}41(42.2) \\
56(57.7)\end{array}$ & $\begin{array}{l}98(18) \\
447(82)\end{array}$ & $3.3,2.1-5.2$ & $<0.001$ \\
\hline
\end{tabular}

PPD: Postpartum depression

Table 2. Recognized risk factors associated with PPD.

\begin{tabular}{|c|c|c|c|c|}
\hline & \multicolumn{2}{|l|}{ PPD } & \multirow{2}{*}{ OR 95\% CI } & \multirow{2}{*}{ Pvalue } \\
\hline & Yes $($ EPDS $) \geq 12$ & No (EPDS) $<12$ & & \\
\hline \multicolumn{5}{|c|}{ Marital satisfaction } \\
\hline Yes & $40(41.2)$ & $472(86.6)$ & \multirow{2}{*}{$(0.1,0.067-6.17)$} & \multirow{2}{*}{$<0.00$} \\
\hline No & $57(58.8)$ & $73(13.3)$ & & \\
\hline \multicolumn{5}{|c|}{ Recent conflict with husband } \\
\hline Yes & $66(68)$ & $126(23.1)$ & \multirow{2}{*}{$(7.0,4.4-11.3)$} & \multirow[t]{2}{*}{$<0.00$} \\
\hline No & $31(13.9)$ & 419 (76.9) & & \\
\hline \multicolumn{5}{|c|}{ Economic problems } \\
\hline Yes & $64(66)$ & $187(34.3)$ & \multirow{2}{*}{$(3.7,2.35-5.85)$} & \multirow[t]{2}{*}{$<0.00$} \\
\hline No & $33(34)$ & $358(65.7)$ & & \\
\hline \multicolumn{5}{|l|}{ Loss of job } \\
\hline Yes & $51(52.5)$ & $60(11)$ & \multirow[b]{2}{*}{$(8.4,5.23-13.6)$} & \multirow[t]{2}{*}{$<0.00$} \\
\hline No & $46(47.4)$ & $458(89)$ & & \\
\hline \multicolumn{5}{|c|}{ Unwanted pregnancy } \\
\hline Yes & $50(51.5)$ & $32(5.8)$ & \multirow{3}{*}{$(17.0,9.9-29.1)$} & \multirow[t]{2}{*}{$<0.00$} \\
\hline No & $47(48.4)$ & $513(94.1)$ & & \\
\hline \multicolumn{4}{|c|}{ Partner support } & \\
\hline Yes & $53(54.6)$ & $237(43.4)$ & \multirow{2}{*}{$1.5,1.0-2.4$} & \multirow[t]{2}{*}{.04} \\
\hline No & $44(45.3)$ & $308(56.5)$ & & \\
\hline \multicolumn{5}{|c|}{ Pregnancy health problems } \\
\hline Yes & $73(75.2)$ & $82(15)$ & \multirow{3}{*}{$17.1,10.2-28.8$} & $<0.00$ \\
\hline No & $24(24.7)$ & $463(84.9)$ & & \\
\hline Child birth & & & & \\
\hline Yes & $28(28.9)$ & $22(4)$ & & $<0.00$ \\
\hline No & $69(71.1)$ & $523(96)$ & $9.6,5.2-17.7$ & \\
\hline Delivery & & & & \\
\hline Premature & $6(6.1)$ & $27(4.9)$ & & 0.6 \\
\hline Term & $91(93.8)$ & $518(95)$ & $1.2,0.5-3.1$ & \\
\hline Place of de & & & & \\
\hline Hospital & $61(62.9)$ & $446(81.8)$ & & $<0.01$ \\
\hline Home & & & $0.37,0.2-0.5$ & \\
\hline Mode of de & & & & \\
\hline Cesarean & $12(12.3)$ & $67(12.2)$ & & 0.98 \\
\hline Vaginal & 85 (87.6) & $478(87.7)$ & $1.0,4.52-1.9$ & \\
\hline Postpartum & & & & \\
\hline Yes & $9(9.2)$ & $38(7)$ & & 0.42 \\
\hline No & $88(90.7)$ & 507 (93) & $1.3,0.63-2.9$ & \\
\hline Sex of infa & & & & \\
\hline Male & $54(55.6)$ & 267 (49) & & 0.22 \\
\hline Female & $43(44.3)$ & $278(51)$ & $1.3,0.84-20$ & \\
\hline Newborn $\mathrm{h}$ & & & & \\
\hline Yes & $30(30.9)$ & $87(4.9)$ & & .000 \\
\hline No & $67(69)$ & $458(84)$ & $2.35,1.4-3.8$ & \\
\hline Breast feed & & & & \\
\hline Yes & $22(22.7)$ & $27(4.9)$ & & $<0.00$ \\
\hline No & $75(77.3)$ & $518(95)$ & $5.6,3.0-10.3$ & \\
\hline
\end{tabular}

\section{Discussion}

The results of the current study showed that the incidence of PPD among women who screened by EPDS was $15.1 \%$. This finding is similar to the reported prevalence of $10-15 \%$ of women who have recently given birth [2]. Fairbrother $N$, in recent study reported prevalence ranges between $11-21 \%$ [9]. Another study from Africa observed higher incidence as $23.4 \%$ [10]. However, there is variability in the prevalence of PPD across different geographical locations and population groups. As regards the variables associated with PPD, they 
are quite consistent with those reported in literature. The current study found that unwanted pregnancy, and pregnancy health problems such as anxiety were the most significantly associated risk factors for PPD. Women who have had unwanted pregnancy or exposed to stressful conditions during pregnancy are more likely to develop PPD, similar to another study [8]. Rich - Edwards JW [11] detected a significant association between unwanted pregnancy and PPD.

The present study observed that the recent conflict with husbands / family, financial hardship and loss of job were associated with an increased odds of PPD. Pregnant women are more easily affected by physical, mental and surrounding changes that cause depressive mood [12], and the partner plays a major role, thus conflict with the partner is considered a potential risk factor for PPD [13]. Chang FW et $a l$ in recent study (2016) found that the difficult economic conditions are associated with PPD and the PPD incidence has a positive correlation with an unemployment rate [14]. However, it is expected that the long-lasting conflict within the country has a great influence on the economic contraction that primarily affected families, as they need more money to raise their babies and to afford their living cost. The greater economic hardship, the more mental stress the mothers experienced. The results of our study showed that childbirth complications and newborn health problems were significantly associated with an increased odds of PPD, similar to another study [15]. Childbirth is the time when mother perceived high level of stress and in this situation often co-exist with other additional stressful events such as financial hardship and limited marital support that could undoubtedly influence development of PPD. Similarly, experiences of stress immediately following delivery such as problems related to infant's temperament, difficulties in recovering one's physical health, caring with premature infants and sleeping problems may play an important role in PPD [16]. The association between not attempting breastfeeding and risk of PPD is controversy, Pope CJ et al [17] concluded that breastfeeding status alone may not be a significant risk factor for PPD. However, this study examined the breastfeeding difficulties and found positive association with risk of PPD, similar to another study [10]. It is therefore, suggested that infant's illnesses, prematurity, maternal perception of infant health status together with lack of support, are significant contributors to PPD. This study did not detect any significant relationship between PPD and maternal age, parity, marital status, place and mode of delivery, similar to other study [18].

The present study found that the educational level of maternal scored positive at EPDS was not significantly related to PPD. This finding is in agreement with other studies [8], [16].

The study limitations were that, the study recruited only women who attended post partum clinics for follow - up during $4-6$ weeks after childbirth, so the results could not be generalizable because women who attended postnatal care could have more favourable psychosocial environment than those who did not attend. In addition, some women may not answer the question correctly thus, recall bias might be present.

The authors suggest that further multi - center studies with large sample size to validate these findings and to provide true magnitude of this problem is required.

\section{Conclusion}

This study revealed a high incidence of PPD, which is unfortunately, seemed invisible issue. Women who developed this condition mostly had disadvantage and unstable psychosocial profiles. Recent conflict with husband, anxiety during pregnancy, unwanted pregnancy, and child care difficulties showed a strong relationship to the development of PPD. Based on these findings, we recommend that screening of women during post partum period is a priority.

\section{Acknowledgments}

The authors would like to thank Dr Saber Al-Sobaihi Global public health, Tokyo Medical and Dental University who contributed to the statistical analysis.

\section{References}

[1] Knights JE, Salvatore ML, Simpkins G, Hunter K, Khandelwal M. In search of best practice for postpartum depression screening: is once enough? European Journal of Obstetrics \& Gynecology and Reproductive Biology 206 (2016) 99-104.

[2] Sharma V, Sharma P. Postpartum depression: diagnostic and treatment issues. J Obstet Gynaecol Can 2012; 34 (5): 436442 .

[3] Gavin NI, Gaynes BN, Lohr KN, Meltzer-Brody S, Gartleher G, Swinson T. Perinatal depression: a systematic review of prevalence and incidence. Obstet Gynecol 2005; 106: 107183.

[4] Bennett, H. A., Einarson, A., Taddio, A, Koren G, Einarson TR. Prevalence of depression during pregnancy: systemic review. Obstetrics and Gynecology. 2004; 103 (4), 698-709.

[5] Bowes WA, Katz VL. Postpartum care in: Gabbe, Steven G. Obstetrics: Normal and Problem Pregnancies. Sixth edition. 2012; Philadelphia, PA: Elsevier/Saunders, chapter 21: 701726.

[6] Robertson E, Grace S, Wallington T, Stewart DE. Antenatal risk factors for postpartum depression: a synthesis of recent literature. Gen Hosp Psychiatry 2004; 26: 289-95.

[7] Bobo WV, Yawn BP. Concise review for physicians and other clinicians: postpartum depression. Mayo Clin Proc 2014; 89: 835-44.

[8] Roomruangwong C, Withayavanitchai S, Maes M. Antenatal and postnatal risk factors of postpartum depression symptoms in Thai women: A case-control study. Sexual \& Reproductive Healthcare 10 (2016) 25-31. 
[9] Fairbrother N, Janssen P, Antony MM, Tucker E, Young AH. Perinatal anxiety disorder prevalence and incidence. J Affect Disord 2016; 200: 148-55.

[10] Adama ND, Foumane P, Olen JPK, Dohbit JS, Um Meka EN, Mboudou E. Prevalence and Risk Factors of Postpartum Depression in Yaounde, Cameroon. Open Journal of Obstetrics and Gynecology, 2015, 5, 608-617.

[11] Rich-Edwards JW, Kleinman KP, Abrams A, Harlow BL, McLaughlin TJ, Joffe H. Sociodemographic predictors of antenatal and postpartum depressive symptoms among women in a medical group practice. J Epidemiol Comm Health 2006; 60: 221-7.

[12] Norhayati, M. N., Hazlina, N. N., Asrenee, A. R., Emilin, W. W. Magnitude and risk factors for postpartum symptoms: aliterature review. J. Affect. Disord. 2015; 175, 34-52.

[13] Husain, N., Bevc, I., Husain, M., Chaudhry, I. B., Atif, N. and Rahman, A. Prevalence and Social Correlates of Postnatal Depression in a Low Income Country. Archives of Women's Mental Health, 2006; 9, 197-202.

[14] Chang F W, Lee W Y, Liu Y P, Yang J J, Chen S P, Cheng h
$\mathrm{K} \mathrm{C} \mathrm{Et} \mathrm{al.} \mathrm{The} \mathrm{relationship} \mathrm{between} \mathrm{economic} \mathrm{conditions} \mathrm{and}$ postpartum depression in Taiwan: a nationwide populationbased study. Journal of Affective Disorders 2016; 204: 174 179 .

[15] Fisher S D, Wisner K L, Clark C T, Sit D K, Luther J F, Wisniew $\mathrm{S}$ et al. Factors associated with onset timing, symptoms, and severity of depression identified in the postpartumperiod. Journal of Affective Disorders 2016; 203: 111-120.

[16] Palumbo G, Mirabella F, Gigantesco A. Positive screening and risk factors for postpartum depression. European Psychiatry 2017; 42: 77-85.

[17] Pope C, Mazmanian D, Bedard M, Sharma V. Breastfeeding and postpartum depression: assessing the influence of breastfeeding intention and other risk factors. J Affect Disord. 2016; 19 (200): 45-50.

[18] Corrêa H, e Couto TC, Santos W, Romano-Silva MA, Santos LM. Postpartum depression symptoms among Amazonian and Northeast Brazilian women. Journal of Affective Disorders. 2016 Nov 1; 204: 214-8. 